\title{
The Standardisation of Radium Ampoules for Therapeutic Use.
}

$A \mathrm{~N}$ apparatus for the routine standardisation of ampoules containing radium compounds and emanation by the $\gamma$-ray ionisation method was installed recently at the Institut Curie. It consists, as

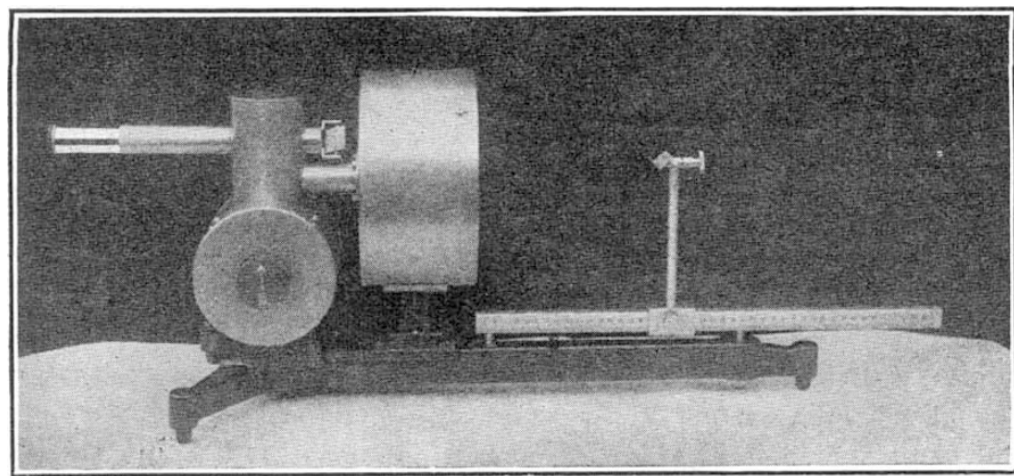

FIG. I.-Apparatus for the standardisation of radium ampoules (one-tenth full size).

shown in Figs. I and 2, of a screened ionisation chamber A connected directly to a gold-leaf electroscope $B$. The ampoule to be tested is placed in an aluminium tray on the support $C$, which can be slid along a graduated rule D. The intensity of the ionisation current is deduced

from the rate of fall of the gold-leaf.

A novel feature of the apparatus is the method of charging the electroscope by means of a variable multicellular condenser $\mathbf{E}$, which obviates the need for a high-voltage battery.

The fixed plates of the condenser are connected to the frame, whilst the movable plates are mounted on a spindle actuated by an ebonite knob. When the condenser is in the position of maximum capacity a projecting finger $F$ brings the movable plates momentarily into contact with the stem $\mathrm{H}$, to which is connected a low-voltage battery (10-20 volts). On turning the movable plates through $180^{\circ}$ the same finger comes into contact with another stem $\mathrm{J}$ connected to the electroscope; at this instant the capacity head. of the condenser is at its minimum and the potential proportionately increased (about thirty times).

The gold-leaf is observed by means of a microscope $\mathrm{K}$ the eyepiece of which is fitted with an angular scale; a small mirror $L$ serves to illuminate the field of the microscope. The ionisation chamber consists of a cylindrical brass box containing a thin aluminium disc $M$, which is connected to the electroscope through the amber-insulated $\operatorname{rod} N$. The end of the box facing the ampoule is closed by a screen consisting of two lead plates each $5 \mathrm{~mm}$. thick.

A modification of the apparatus is used for measuring the radio-activity of ores, earths, etc. The electroscope, the charging condenser, and the substance to be tested occupy separate compartments of a cylindrical brass box. The radio-active substance is placed on a tray immediately underneath a rounded stem, the upper end of which forms the pillar of the electroscope. The latter is charged by means of a variable condenser identical with the one previously described, but it can, if desired, be charged independently or connected to a separate ionisation chamber.

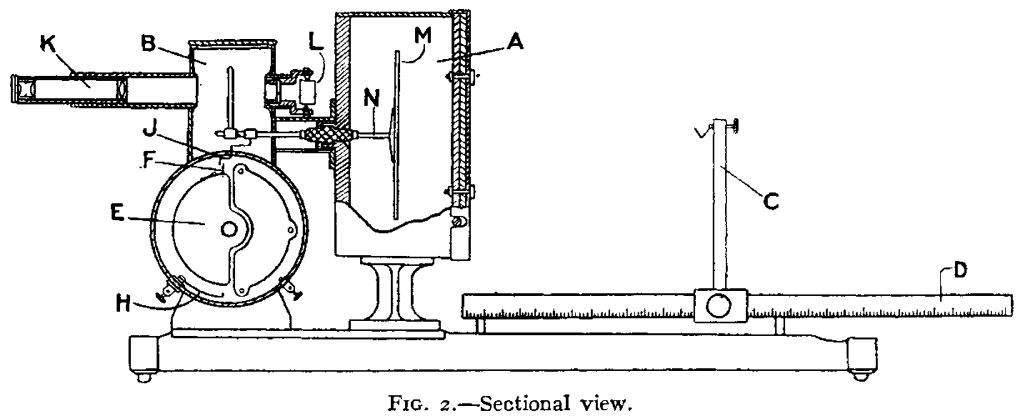

The electroscope is "earthed" by turning a milled

Both instruments were designed by M. Holweck, of the Institut Curie, in collaboration with the manufacturer, M. Beaudouin, Paris.

\section{Life-cycles of Bacteria.}

I $\mathrm{N}$ a preliminary communication published in 1916 1 Dr. Lönis expressed the view that all bacteria pass through a definite life-cycle, and the present publication $^{1}$ is an extensive review of the literature in support of that contention. The volume also includes a chapter on methods, an extensive bibliography, and more than $35^{\circ}$ microphotographs of the forms observed.

Briefly, the life-cycle is as follows:-Under certain conditions the cells come together and fuse, forming an amorphous mass-the symplastic stagein which the protoplasm undergoes a thorough mixing. The symplastic stage is formed not only in cultures in artificial media, but, in the case of the

1 Part $x$, Review of the Literature $(1838-10 \times 8)$. By Dr. F. Lobnis. National Academy of Sciences, Washington, vol. 16, second Memoir. Pp. $252+4$ I plates.

NO. 2730, VOL. IO9] pathogenic organisms, in the body of the host as well. It forms the connecting link between the various subcycles of which the life-cycle of the organism may be composed. All kinds of vegetative cells, as well as all the varieties of reproductive organs described by the author, can give rise to the symplastic stage. From the symplasm the so-called regenerative units always arise, and these either grow into new cells or several of them unite to form new cells directly.

Six distinct types of reproductive organs have been described by the author. These are:-(I) Gonidia, two to four or more in each cell. They are generally motile and slightly more resistant than vegetative cells, Many are filter passers. They grow into vegetative cells. (2) Regenerative bodies, distinct from regenerative units. They are spherical, oval, 
pear- or kidney-shaped or more or less irregular, rodshaped, and branched. They are readily stainable, generally motile, and fairly resistant. They may multiply by fission or budding, are formed from vegetative cells or from the symplasm, and may give rise to vegetative cells or to the symplastic stage. (3) Exospores, unstainable regenerative bodies. (4) Endospores, produced by vegetative cells or by regenerative bodies. Conditions for formation are similar to those for the formation of regenerative bodies. (5) Arthrospores, easily stainable, but withstand drying better than heating. They are formed by the segmentation of vegetative cells and transformation of the joints into fairly resistant spherical bodies. (6) Microcysts, very similar to arthrospores. They are formed by vegetative cells growing and becoming spherical with a thickened membrane. After a rest period they may become vegetative cells, germinate like spores, or may break up into two, three, or four segments, which become vegetative cells. In addition to their reproductive function exospores, endospores, arthrospores, and microcysts are, in the first place, resting-stages.
Besides the formation of the symplasm a second mode of interaction between the protoplasmic bodies in bacterial cells has been observed. This consists in the union of two or more cells, and is termed "conjunction" by the author. Conjunction is most common in cultures two to four days old, and generally precedes the formation of gonidia, reproductive bodies, exospores, and endospores.

The publication brings together an overwhelming amount of evidence as to the existence of the various forms distinguished by the author. The arrangement of these forms in the life-cycles of the bacteria is a point on which further information is desirable, but this will, doubtless, be provided in the later publication in which the observations of the author are to be dealt with in detail. From the point of view of the student of bacterial morphology the publication must be regarded as one of first-rate importance. The general worker on bacteriological problems will also find in it much information of a highly valuable nature, and doubtless will be able to confirm the existence of many of the forms observed from the results of his own experience.

\section{Miners' Lamps. ${ }^{1}$}

$\mathrm{O}^{\mathrm{F}}$ late years there has been a tendency on the part of makers of miners' safety lamps to employ thin sheet-metal, perforated with holes of small diameter, to serve the same purpose as wire gauzethat is to say, with holes large enough to admit of the passage of the necessary volume of air through them, but small enough to arrest the passage of flame. It will be recalled that the lamp invented by George Stephenson depended upon perforated sheetcopper for its impermeability to flame. A further innovation that has recently been gaining ground is the addition of a short glass cylinder, known as the "combustion tube," to the lower end of a metal chimney suspended directly above the flame of the lamp. This contrivance promotes a better circulation of air in the lamp, keeps the products of combus. tion separate from the incoming air, and, as a consequence, produces a brighter flame and enhances the lighting power of the lamp.

Metal chimneys have long been employed with this object, notably in the Mueseler lamp-the only kind of safety lamp permitted in Belgian mines-but as the bottom of the metal chimney canrot be brought lower down than the top of the flame without obstructing

3 Mines Department. Miners' Lamps Committee. Memorandum No. 4 : Record of research on the passage of flame through perforat $d$ plates and through perforated tubes of small diameter. Pp. $12+6$ plates. (H.M.S.O.) gd. net. Memorandum No. 5: Record of recearch on the passage of the flame of an explosion fron within miners' lamps fitted with chimneys. Pp. r2. (H.M.S.O.) 6d. net. the light, the benefit derived from their use is limited. In this respect the glass extension is distinctly beneficial.

Having regard to the changes of this kind which were taking place in the construction of safety lamps, the Home Secretary appointed the Miners' Lamps Committee in 1919 to inquire into, and report on, various questions relating to safety lamps, and the Secretary for Mines re-appointed the same Committee in January, I92I. Up to the present the Committee has issued five Memoranda, of which the last two, Nos. 4 and 5 , issued in the end of last year, deal with the use of perforated metal plates and chimneys respectively.

The experiments described in Memorandum No. 4 were made to ascertain the relative resistance to the passage of flame possessed by metal plates of various thicknesses perforated with holes of various diameters; and those described in Memorandum No. 5 to ascertain the relative resistance of chimneys of various lengths and diameters at top and bottom and extending to higher or lower levels above and below the wire gauze diaphragm by which they are supported.

The results are tabulated in both memoranda and in the letter to the Secretary for Mines which accompanies each the chairman of the Committee makes certain recommendations and suggestions founded on these results. The total cost of the Committee's inquiry to date (November, 192 I) is given as $5550 l$.

\section{Pébrine in Silkworms.}

$\mathrm{N}$ an interesting report on pébrine in silkworms in India (Memoirs Dept. Agric. in India, Bacteriological Series, vol. I, No. 8, November, 1920, pp. 75, 26 plates), Mr. C. M. Hutchinson gives an account of experimental work on methods of infection. He found infected ova in the pupal ovary, and the infection is traced in the egg, larva, and pupa-and recounts the life-history of the causal organism, Nosema bombycis. The Pasteur method of searching for the organism, devised more than fifty years ago, consists in crushing the body of the moth in a mortar, and examining, under a magnification of about 600 , a small fraction of the resulting powder in a drop of water, to ascertain if the characteristic spores of Nosema are present. This method, according to the author, has not been attended in India with any approach to the measure of success which has been attained in Europe. The chances of non-detection of infected moths, and the risk of spreading the spores (due to careless application of the method) in the rooms used for examining the moths, are considerable-the author states that he has seldom failed to find Nosema spores in the floor dust from these rooms, even in cases where the floors were of concrete. In Europe a period of several months elapses between oviposition by the moth and hatching of the eggs, so 